\title{
IMPLEMENTASI WEBSITE PROFIL SMP N 2 KARTASURA
}

\author{
Intan Larasati ${ }^{1}$, Sri Hajiati ${ }^{2}$, Rayyan \\ Hanugrah $^{3}$, Dimas Aryo Anggoro ${ }^{4}$ \\ Program Studi Informatika, Fakultas \\ Komunikasi dan Informatika, \\ Universitas Muhammadiyah Surakarta \\ 1200170091@student.ums.ac.id \\ 1200170103@student.ums.ac.id \\ 1200170109@student.ums.ac.id \\ dimas.a.anggoro@ums.ac.id \\ *correspoinding author
}

Naskah dikirim: 12 November 2020 Naskah direvisi: 16 Desember 2020

Naskah diterima: 17 Desember 2020

\begin{abstract}
ABSTRAK
Website merupakan media informasi yang dapat dimanfaatkan sebagai sarana memperkenalkan atau mempromosikan diri bagi suatu organisasi atau institusi. Sekolah adalah salah satu institusi yang sering menggunakan website sebagai media promosinya untuk lebih menarik calon siswa maupun masyarakat umum. SMP Negeri 2 Kartasura merupakan sebuah institusi yang berada dibawah pengawasan Dinas Pendidikan dan Kebudayaan Kabupaten Sukoharjo. Sebagai salah satu instansi pendidikan SMP Negeri 2 Kartasura mengalami kendala dalam bidang teknologi serta tenaga ahli dalam mengelola website resmi sebagai sumber informasi bagi siswa, orang tua wali, dan masyarakat umum. Sebelumnya websiteresmi sudah pernah dibuat oleh pihak ketiga, akan tetapi belum dipergunakansecara maksimal oleh pihak sekolah dikarenakan terkendala tenaga ahli yangkurang dan website yang dibangun masih belum tertata dengan baik, hal inimenyebabkan website tidak bisa diakses kembali. Tujuan website tersebut dibuatdipergunakan sebagai sarana media promosi yang dapat digunakan untukmemperlancar proses bertukarnya sebuah informasi yang diinginkan olehpengunjung. Hasil dariwebsite tersebut pengunjung dapat mengetahui secara rinci bagaimana kegiatanakademik, prestasi, dan informasi mengenai SMP Negeri 2 Kartasura. Dengan adanya website tersebut,membantu sekolah untuk memberikan informasi secara detail mengenai sekolah kepada calon murid yang ingin mendaftar ke SMP Negeri 2 Kartasura.
\end{abstract}

KATA KUNCI : Informasi, SMP N 2 kartasura, Website Profil

\section{PENDAHULUAN}

Memasuki era globalisasi saat ini teknologi informasi semakin canggih dan mudah dalam memanfaatkan fasilitas internet. Dalam menggunakan teknologi internet sudah menjadi kebutuhan semua pihak [1]. Saat ini banyak situs web di internet digunakan sebagai wadah segala sumber informasi secara global. Banyak kalangan bisnis dan lembaga pemerintah yang memanfaatkan website guna menyebarluaskan layanan dan informasi [2].

Website merupakan media informasi berbasis jaringan komputer yang dapat diakses dimana saja dengan biaya yang relatif[3]. Perkembangan website saat ini demikian cepat, hal ini disebabkan oleh beberapa faktor diantaranya perkembangan infrastruktur yang cukup pesat seperti internet[4]. Penggunaan website diharapkan dapat membantu kelancaran dan mempercepat proses penyajian informasi yang mudah dan akurat. Website yang mampu mengemas informasi baik berupa berita maupun gambar secara menarik memiliki daya tarik tersendiri bagi pengunjungnya. Salah satu upaya untuk meningkatkan ekstensi dalam lembaga pendidikan adalah pembuatan sebuah website sekolah [5].
Berdasarkan hasil dari wawancara yang telah dilakukan dengan pihak SMP Negeri 2 Kartasura, diketahui bahwa SMP Negeri 2 Kartasura belum memiliki media penyampaian informasi yang efektif. Segala informasi yang berhubungan dengan sekolah meliputi sejarah singkat, visi dan misi, fasilitas, prestasi, kurikulum, ekstrakurikuler, tata tertib, struktur organisasi, kepala sekolah, guru dan karyawan, siswa, kegiatan-kegiatan sekolah harus diakses langsung di lokasi sekolah berada. Meskipun informasi dapat diakses di lokasi sekolah berada, tetapi hal ini tidak mudah dan tidak efektif bagi masyarakat yang ingin mengetahui informasi mengenai SMP Negeri 2 Kartasura.Maka perlu dikembangkan sebuah media yang mampu berperan sebagai alat pendistribusian informasi yang lebih efektif dan efisien. Diharapkan dengan adanya pembuatan website profil ini sebagai sarana informasi dari sekolah tersebut dapat mempermudah penyampaian informasi dari sekolah tersebut kepada masyarakat luas, sehingga informasi lebih cepat diterima dan dapat diakses dari manapun dan kapanpun. Pembuatan website ini dilaksanan dalam kurun waktu dua bulan, dimulai pada bulan april dan selesai pada bulan mei 2020. 


\section{TINJAUAN PUSTAKA}

A. Website

Web adalah salah satu aplikasi yang berisikan dokumen-dokumen multimedia dapat berupa teks, gambar, suara, animasi, maupun video yang menggunakan protokol HTTP, web biasanya diakses melalui perangkat lunak yang disebut browser[6].

B. Xampp

Xampp merupakan software web server apache yang didalamnya tertananm server MySQL yang didukung dengan bahasa pemrograman PHP [7].

C. PHP

PHP merupakan salah satu bahasa pemrograman yang beralan dalam sebuah web server dan berfungsi sebagai pengolah data pada sebuah server[8]. PHP dirancang untuk membentuk web dinamis, hal tersebut berarti PHP dapat membentuk suatu tampilan berdasarkan permintaan terkini [9].

D. MySQL

Mysql merupakan sebuah perangkat lunak yang digunakan untuk wadah penyimpanan data. Mysql turunan dari konsep utama pada database sejak lama, yaitu SQL. Sql digunakan untuk pemilihan atau pemasukan data yang dikerjakan dengan mudah dan secara otomatis [10].

\section{METODE PENGABDIAN}

Metode yang digunakan penulis dalam melakukan pengabdian ini antara lain :

A. Metodologi Analisis Kebutuhan Sistem

a. Kebutuhan Fungsional

1. Website dapat memberikan tampilan yang mudah dipahami.

2. Website dapat memberikan bahasa dan istilah yang mudah dimengerti.

3. Website dapat memberikan data informasi lengkap yang dibutuhkan pengguna.

4. Website dapat meberikan gambar serta penjelasan yang memudahkan pengguna.

5. Website dapat meningkatkan pelayanan dalam penyebaran informasi untuk guru, siswa, maupun masyarakat umum.

b. Kebutuhan Non Fungsional

Kebutuhan Non Fungsional mencakup kebutuhan perangkat keras (hardware) dan perangkat lunak(software) dari aplikasi yang akan dibangun, dimana didalamnya memuat antara lain :

1. Perangkat Keras(Hardware)

Untuk membuat website company profile SMP Negeri 2 Kartasura menggunakan laptop dengan spesifikasi sebagai berikut :

a) Prosesor : Intel Core i5-7200U
b) Memory
: 4GB
c) HDD
: 1TB
d) VGA 930MX
: NVIDIA GeForce
e) Mouse

2. Perangkat Lunak(Software)

Dalam proses pembuatan Website Company Profile SMP Negeri 2 Kartasura dibutuhkan beberapa perangkat lunak, yaitu :
a) Sistem Operasi Windows 10
b) Apache
c) Google Chrome
d) Text Editor

B. Metode Pengumpulan Data

1. Metode Observasi

Metode observasi merupakan sebuah metode pengempulan data dengan cara mengamati secara langsung objek yang akan diteliti serta mencari tahu informasi yang sudah ada sebelumnya.

2. Metode Wawancara atau Interview

Metode pengumpulan data dengan cara mencari informasi dengan mengajukan pertanyaan-pertanyaan secara langsung kepada phak yang bersangkutan sebagai narasumber. Kemudian menampung semua informasi yang telah diberikan oleh narasumber sebagai sebuah data informasi.

3. Metode Perancangan Website

a. Gambar dibawah ini menjelaskan mengenai sitemap website company profile. Yang berisikan mengenai menu dan submenu yang akan tampil pada website.

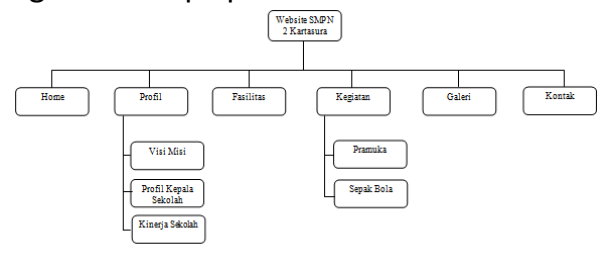

Gambar 1. Sitemap website SMP N 2 Kartasura

b. Gambar dibawah ini menjelaskan mengenai sitemap admin website company profile. Yang berisikan mengenai semua hal yang harus terdapat dalam admin website company profile.

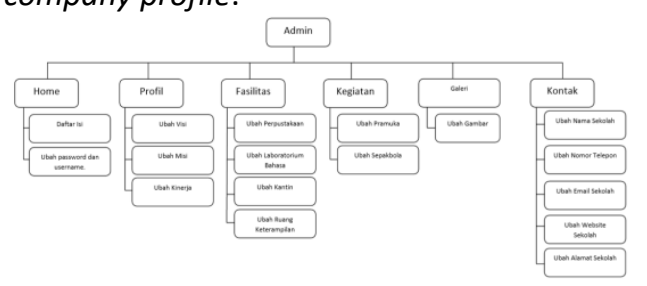

Gambar 2. Sitemap halaman admin website SMP N 2 Kartasura 


\section{HASIL DAN ANALISA}

Website Company Profile dikelola oleh admin yang dapat melakukan input data dan menampilkan data yang telah dimasukkan, mengedit data, serta menghapus data. Semua data yang telah dimasukkan tersimpan di database untuk dikelola oleh admin.

\section{A. Halaman Login Admin}

Halaman login merupakan halaman yang digunakan untuk verifikasi user yang akan masuk kehalaman admin dengan cara meminta user untuk memasukkan pasword yang dimiliki. Berikut tampilan halaman login.

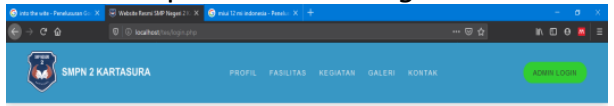

Silahkan Login Sebagai Admin

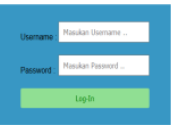

Gambar 3. Halaman login admin

B. Halaman Home Admin

Halaman yang akan muncul pertama kali ketika telah berhasil untuk login setelah diverifikasi.

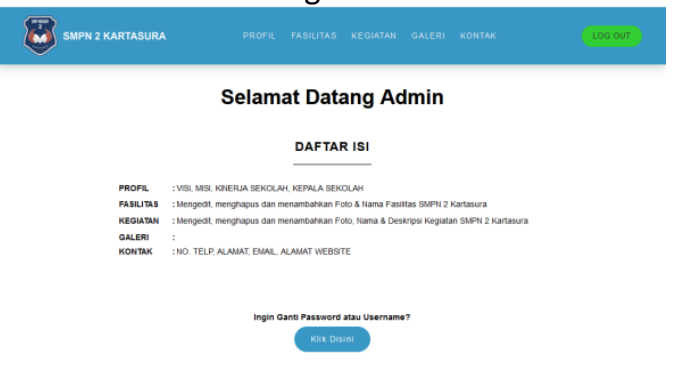

Gambar 4. Halaman home admin

C. HalamanUpdate Profil

Halamanini digunakan untuk menambah, mengedit maupun menghapus visi, misi, dan kinerja SMP N 2 Kartasura.

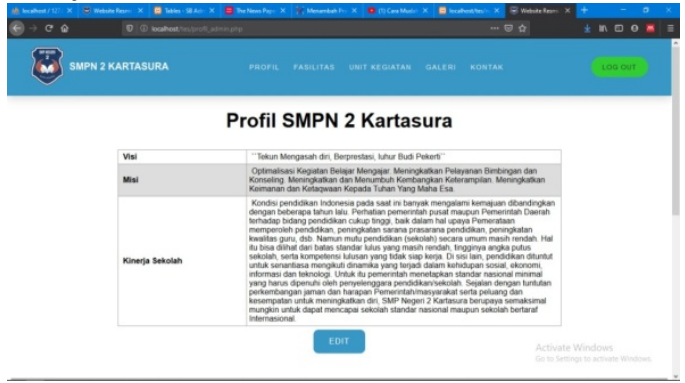

Gambar 5. Halaman update profil

D. Halaman Update Profil Kepala SMP N 2 Kartasura

Halaman ini digunakan untuk menambah, mengedit, maupun mengapus informasi profil Kepala SMP N 2 Kartasura.

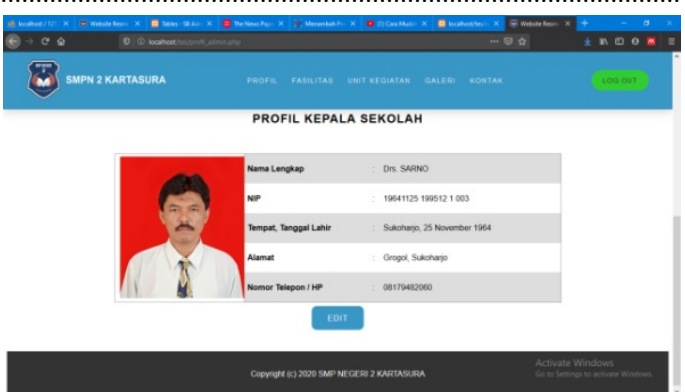

Gambar 6. Halaman update profil kepala sekolah

E. Halaman Admin Update Fasilitas

Halaman ini digunakan untuk menamba, mengedit, maupun menghapus informasi fasilitas yang ada di SMP N 2 Kartasura.

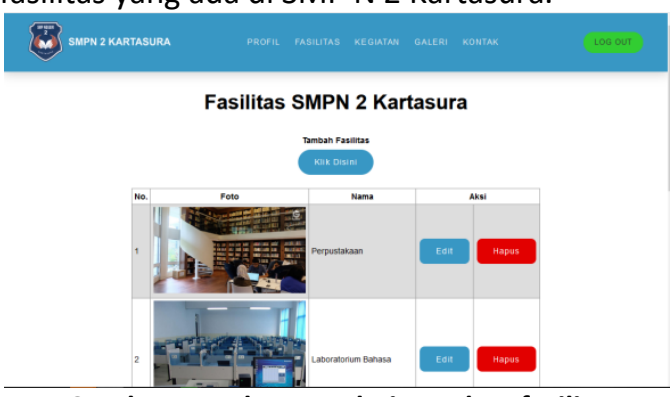

Gambar 7. Halaman admin update fasilitas

F. Halaman Admin Update Kegiatan

Halaman ini digunakan untuk menambah, mengedit, maupun menghapus informasi kegiatan siswa SMP N 2 Kartasura.

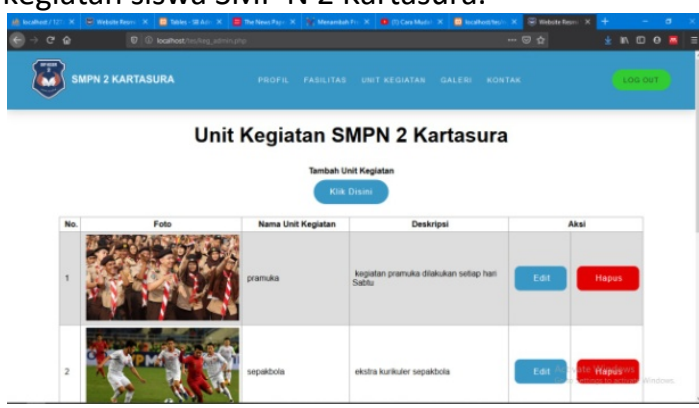

Gambar 8. Halaman admin update kegiatan

G. Halaman Admin Update Galeri

Halaman ini digunakan untuk menambah, mengedit, maupun menghapus dokumentasi dari berbagi fasilitas dan kegiatan di SMP N 2 Kartasura.

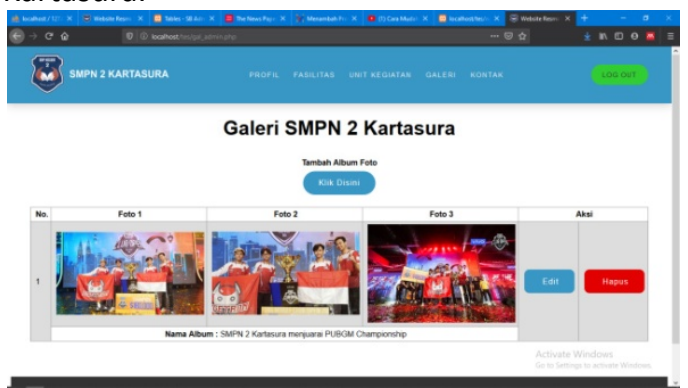

Gambar 9. Halaman Admin Update galeri

H. Halaman Admin Update Kontak

Halaman ini digunakan untuk menambah, 
mengedit, maupun menghapus informasi kontak SMP N 2 Kartasura.

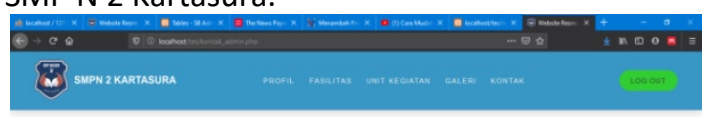

Kontak SMPN 2 Kartasura
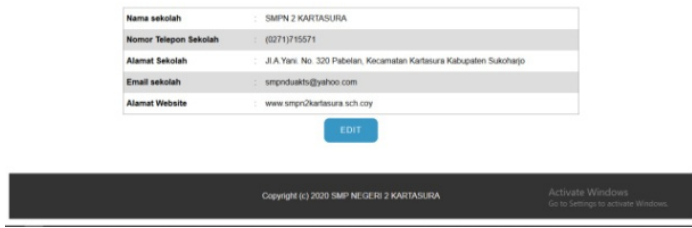

Gambar 10. Halaman admin update kontak

I. Halaman Home

Halaman awal pada website.

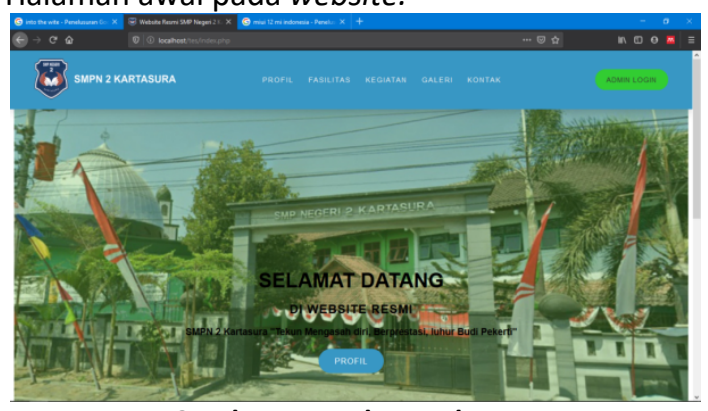

Gambar 11. Halaman home

J. Halaman Menu Profil

Halaman ini berisikan visi, misi, kinerja sekolah, serta profil kepala SMP N 2 Kartasura.

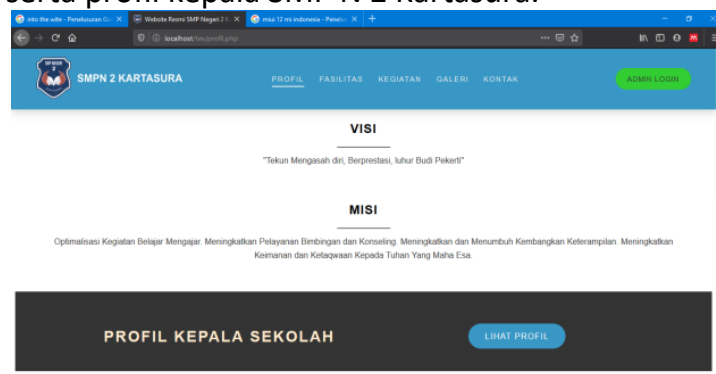

Gambar 12. Tampilan visi misi SMP N 2 Kartasura

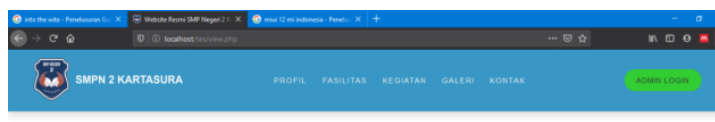

KEPALA SEKOLAH
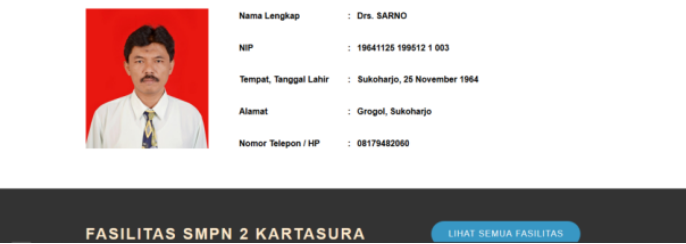

Gambar 13. Tampilan profil Kepala SMP N 2 Kartasura
KINERJA SEKOLAH

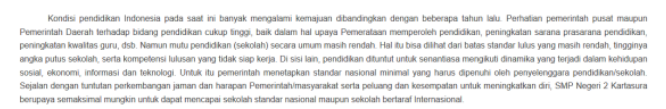

FASILITAS SMPN 2 KARTASURA

CHAT SERUA FASIIAS

Gambar 14. Tampilan kinerja sekolah

K. Halaman Menu Fasilitas

Halaman ini berisikan informasi fasilitas yang dimiliki oleh SMP N 2 Kartasura.

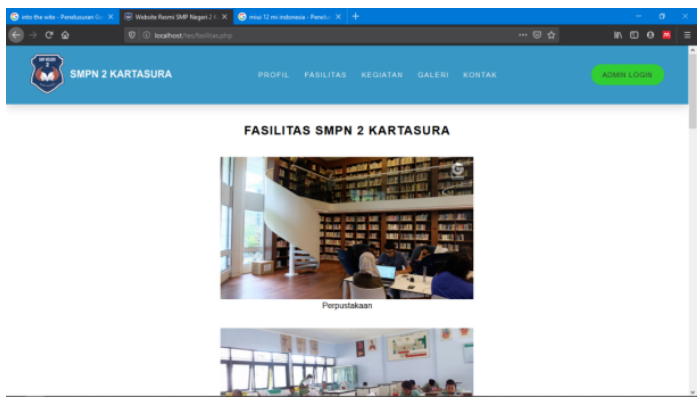

Gambar 15. Halaman menu fasilitas

L. Halaman Menu Kegiatan

Halaman ini berisikan informasi kegiatankegiatan yang ada di SMP N 2 Kartasura.

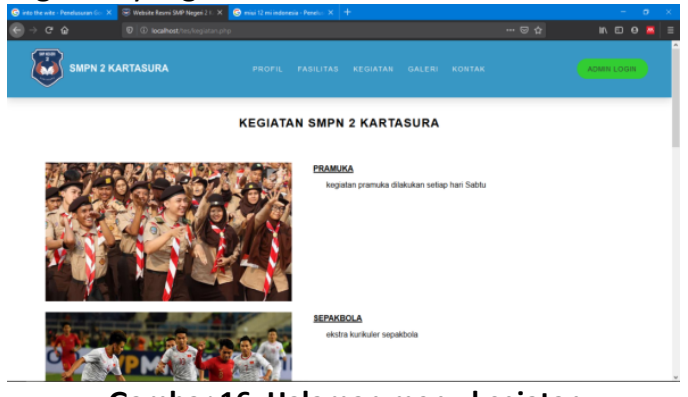

Gambar 16. Halaman menu kegiatan

M. Halaman Menu Galeri

Halaman ini menampilkan foto-foto dokumentasi dari berbagai kegiatan SMP $\mathrm{N} 2$ Kartasura.

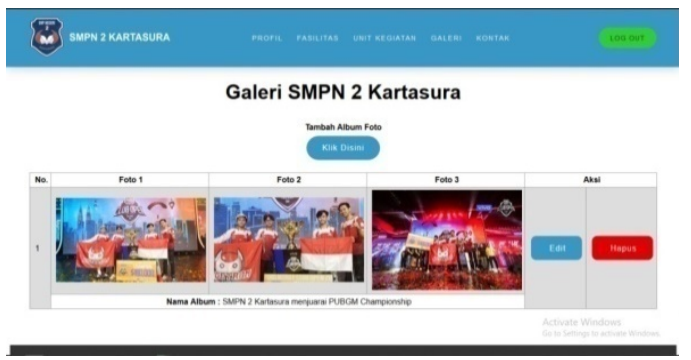

Gambar 17. Halaman menu galeri

N. Halaman Menu Kontak

Menampilkan daftar kontak SMP N 2 Kartasura yang dapat dihubungi. 


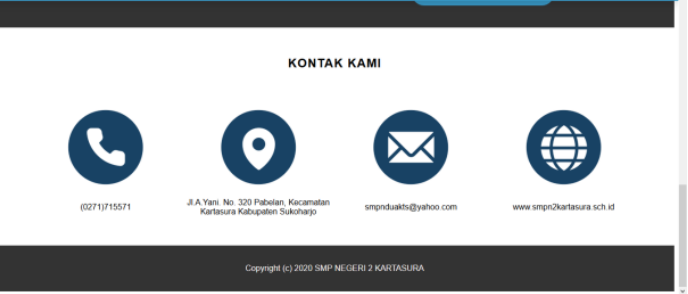

Gambar 18. Halaman menu kontak

\section{PEMBAHASAN}

Website ini merupakan salah satu sarana promosi bagi SMP $\mathrm{N} 2$ Kartasura guna memperkenalkan sekolah ke khalayak luas. Website ini akan memudahkan masyarakat dalam mencari informasi mengenai SMP N 2 Kartasura. Informasi yang dapat diakses berupa profil SMP N 2 kartasura, fasilitas yang dimiliki, kegiatan-kegiatan siswa, serta kinerja sekolah. Tampilan website dibuat sederhana sehingga akan lebih mudah dimengerti penggunanya.

\section{KESIMPULAN DAN SARAN}

Dari hasil yang telah dipaparkan sebelumnya maka dapat disimpulkan bahwa pembuatan website ini mampu memberikan manfaat bagi penulis dalam menerapkan ilmu yang telah dipelajari dan dikembangkan dalam perkuliahan kedalam dunia kerja yang nyata, serta mampu memudahkan admin untuk menampilkan informasi dari pihak sekolah kepada pihak luar secara umum.

Website ini belum dapat dikatakan sempurna karena masih ada beberapa fitur yang dapat dikembangkan agar dapat lebih berguna bagi pengguna. Oleh karena itu, pengembangan website SMP N 2 Kartasura masih diperlukan :

a. Perlunya update berkala agar website selalu aktif.

b. Fitur harus selalu dikembangkan sesuai kebutuhan pengguna.

\section{PERSANTUNAN}

Penulis mengucapkan banyak terima kasih kepada Program Studi Informatika Universitas Muhammadiyah Surakarta karena telah memberikan kesempatan untuk mendapatkan ilmu dan pengalaman dari dunia luar. Pihak Fakultas Komunikasi dan Informatika atas izin dan bantuan yang diberikan sehingga pengabdian ini dapat terlaksana dengan baik. Serta pihak SMP Negeri 2 Kartasura yang telah memberikan izin dan berkenan untuk terlibat dalam pengabdian ini.

\section{DAFTAR PUSTAKA}

[1] D. R. Chandranegara, C. Sri, K. Aditya, and F. D. Setiawan, "Implementasi Website Profile Madrasah Muhammadiya Al-Munawarroh Malang Sebagai Media Informasi Bagi Masyarakat," vol. 4, no. 2, pp. 305-309, 2020.

S. Ariani, M. Diah, and I. Soeksin, "Bimbingan Teknis Pembuatan Website Untuk Meningkatkan Pengetahuan dan Keterampilan Siswa SMP Negeri 1 Tarakan Tahun 2020," vol. 1, no. 1, pp. 35-47, 2020.

[3] K. Rizal, "Rancang Bangun Sistem Informasi Penjualan Obat Berbasis Dekstop dengan Model Waterfall," Swabumi, vol. 6, no. 2, pp. 117-122, 2018, doi: 10.31294/swabumi.v6i2.4558.

[4] A. Anthony, ... A. T.-... I. dan, and undefined 2017, "Analisis dan Perancangan Sistem Informasi Penjualan Berdasarkan Stok Gudang Berbasis Client Server (Studi Kasus Toko Grosir 'Restu Anda')," ratih_wulandari.staff.gunadarma.ac ....

[5] N. R. D. Setyaningsih, D. P. Arini, and ... "Pengembangan Dan Pelatihan Website Sekolah Di Smp Indriasana Palembang," Pros. Semin. ..., pp. 1-7, 2020.

[6] P. S. Hasugian, "Perancangan Website Sebagai Media Promosi Dan Informasi," J. Inform. Pelita Nusant., vol. 3, no. 1, pp. 82-86, 2018.

[7] I. Ardianto and M. R. K. Nst, "Perancangan aplikasi video streaming web menggunakan xampp di universitas al-washliyah labuhanbatu," Infotek, vol. 1, no. 3, pp. 1-6, 2016.

[8] A. Mubarak, "Rancang Bangun Aplikasi Web Sekolah Menggunakan Uml (Unified Modeling Language) Dan Bahasa Pemrograman Php (Php Hypertext Preprocessor) Berorientasi Objek," JIKO (Jurnal Inform. dan Komputer), vol. 2, no. 1, pp. 19-25, 2019, doi: 10.33387/jiko.v2i1.1052.

[9] R. Kurniawan and S. Marhamelda, "Sistem Pengolahan Data Peserta Didik Pada Lkp Prima Tama Komputer Dumai Dengan Menggunakan Bahasa Pemrograman Php," I N F O R M a T I Ka, vol. 11, no. 1, p. 37, 2019, doi: 10.36723/juri.v11i1.153.

[10] D. Maharani, "Perancangan Sistem Informasi Akademik Berbasis Web Pada Sekolah Islam Modern Amanah," vol. 2, no. April, pp. 27-32, 2018, doi: 10.31227/osf.io/r9szc. 